\title{
Daily time series for cardiovascular hospital admissions and previous day's air pollution in London, UK
}

\author{
Jan D Poloniecki, Richard W Atkinson, Antonio Ponce de Leon, H Ross Anderson
}

\begin{abstract}
Objective-To test for a significant association between air pollution and emergency hospital admissions for circulatory diseases (international classification of diseases-9 390-459) in London, England, that would be consistent with a causal effect of pollution on the previous day.

Methods-Long term concurrent trends, temperature, humidity, day of the week, influenza epidemic of 1989 , and cyclical covariations with periodicity $>20$ days in daily measures of pollution and admissions for 1987-94 were allowed for.

Results-There were 373556 admissions. No association was found between $\mathrm{O}_{3}$ and circulatory diseases. Four other pollutants were associated with acute myocardial infarction and circulatory diseases combined. $P$ values and attributable cases (95\% confidence intervals) for acute myocardial infarction were: black smoke $P=0.003,2.5 \%(0.8 \%$ to $4.3 \%)$; $\mathrm{NO}_{2} \mathrm{P}=0.002,2.7 \%(0.8 \%$ to $4.6 \%)$; CO $\mathbf{P}=0.001, \quad 2.1 \% \quad(0.7 \%$ to $3.5 \%)$; and $\mathrm{SO}_{2} \mathrm{P}=0.0006,1.7 \%(0.7 \%$ to $2.6 \%)$. There were also associations between black smoke and angina $(P=0.02), \mathrm{NO}_{2}$ and arrhythmia $(P=0.04)$, and $C O$ and other circulatory diseases $(P=0.004)$, but none with heart failure. Acute myocardial infarction was the only diagnosis for which there were significant associations with and without adjustment for cyclical terms. The associations with acute myocardial infarction were significant only in the cool season.

Conclusion-Population data were consistent with 1 in 50 heart attacks currently presenting at London hospitals being triggered by outdoor air pollution. Further research is now needed to investigate whether background concentrations of black smoke, $\mathrm{NO}_{2}, \mathrm{CO}$, and $\mathrm{SO}_{2}$ are a preventable cause of myocardial infarction. These results, if applied to all myocardial infarctions in the United Kingdom, indicate a potential saving of 6000 heart attacks a year.
\end{abstract}

(Occup Environ Med 1997;54:535-540)

Keywords: air pollution; carbon monoxide; acute myocardial infarction
Biological mechanisms by which air pollution at current levels might cause morbidity and death are speculative, but inflammation of the airways may be a common pathway for several pollutants including particulate matter, ${ }^{1}$ and carbon monoxide (CO) reduces the oxygen transport capability of haemoglobin. Statistical associations between levels of air pollution currently experienced in cities and daily counts of mortality have been explored in more than 30 studies, and reviewers agree that the data indicate a consistent positive association. ${ }^{2-4} \mathrm{Hospi}$ tal admissions for respiratory and cardiovascular diagnoses not restricted to emergencies, and also emergency room use, show consistent associations with air pollution as reviewed by Lipfert. ${ }^{5}$ The diagnosis of the cause of emergency admission to hospital, as confirmed at discharge, is likely to be more closely related to a mechanism by which pollution might act than the underlying cause of death from the death certificate, and will relate to more serious conditions than non-emergency admissions or emergency room visits. We therefore studied emergency admissions to London hospitals 1987-94 for circulatory diseases, which is the largest category of deaths. Associations of admissions were sought with daily measurements of ozone $\left(\mathrm{O}_{3}\right)$, nitrogen dioxide $\left(\mathrm{NO}_{2}\right)$, sulphur dioxide $\left(\mathrm{SO}_{2}\right), \mathrm{CO}$, and black smoke. Although time series data of this type cannot establish causality, close and specific significant associations would encourage controlled experimentation and the search for biological mechanisms.

Previous workers have considered a range of lags from the same day up to 10 days previously for the effect of pollution and meteorology on health. With cumulative combinations these choices generated from three to 20 different lags, from which the most significant associations were presented in the published results. On the other hand, a single choice of lag reduces the multiplicity of tests and hence makes $P$ values more meaningful. Based on published results, our previous work, and physical considerations, but before examining the data on circulatory admissions, we selected a lag of one day. The present investigation looks for significant associations between outdoor metered concentrations of five pollutants from 1987-94 and emergency hospital admissions for circulatory diseases on the next day. 


\section{Methods}

ENVIRONMENTAL MEASUREMENTS

Measurements of $\mathrm{O}_{3}, \mathrm{NO}_{2}, \mathrm{SO}_{2}$, and $\mathrm{CO}$ were from a background monitoring site in central London near a mainline railway station with bus and taxi ranks. $\mathrm{O}_{3}$ was taken as the mean of eight hourly assessments between 0900 and 1700 Greenwich mean time, but was not used if more than two hourly assessments were missing. The $\mathrm{NO}_{2}, \mathrm{SO}_{2}$, and $\mathrm{CO}$ measurements were means of 24 hourly measurements, but were not used if there were less than 18 values. Black smoke was a mean of concentrations from one central site and four suburban sites. Missing values of black smoke at individual sites were interpolated by the method of Buck. ${ }^{6}$ The CO was measured by gas filter correlation. ${ }^{7}$ Measurement techniques for the other pollutants have been described. ${ }^{8}$

Temperature and humidity data were obtained from the Meteorological Office monitoring site in central London. Temperature was taken as the mean of minimum and maximum daily temperatures, or was not used if there were less than 18 hourly values. Humidity was taken as the mean of values taken at 0600 and 1500 , but was not used if either of these values were missing.

\section{CIRCULATORY DISEASES}

Hospital episode statistics data from 1 April 1987 to 31 March 1994 for diseases of the circulatory system, international classification of diseases ninth revision (ICD-9) 390-459, were used. Analyses were performed for the combined group and the following subgroups: acute myocardial infarction (ICD-9 410), angina pectoris (ICD-9 413), other ischaemic heart disease (ICD-9 414), arrhythmia (ICD-9 427), heart failure (ICD-9 428), cerebrovascular disease (ICD-9 430-8), and all remaining codes. The groupings were chosen before the time series data were analysed to give mean daily counts in excess of 10 for London, according to previously published data. ${ }^{9}$ The same definition of London and type of admissions were used as previously. ${ }^{10}$

\section{METHOD OF ANALYSIS}

The objective of the analysis was to find whether there was a significant association between a pollutant and hospital admissions, after allowing for meteorology and calendar variables. The definition and selection of model components was based on the scheme used by APHEA. ${ }^{11}$

A starting date for a six week period around the influenza epidemic at the end of 1989 was identified between 25 October and 4 Decem-

Table 1 Number of admissions per day for cardiovascular diagnoses in London 1987-94 (selected percentiles and mean)

\begin{tabular}{llcrrrr}
\hline ICD-9 Code & Diagnosis & Median & $10 \%$ & $90 \%$ & Max & Mean \\
\hline 410 & Acute myocardial infarction & 26 & 17 & 36 & 60 & 26.7 \\
413 & Angina pectoris & 15 & 7 & 24 & 36 & 15.4 \\
414 & Other ischaemic heart disease & 10 & 5 & 15 & 26 & 10.0 \\
427 & Cardiac dysrhythmia & 11 & 5 & 19 & 36 & 11.9 \\
428 & Heart failure & 24 & 13 & 38 & 64 & 24.6 \\
$430-8$ & Cerebrovascular & 28 & 17 & 39 & 59 & 28.2 \\
Other & Other circulatory & 28 & 14 & 46 & 70 & 29.5 \\
$390-459$ & Circulatory system & 144 & 90 & 200 & 253 & 145.1 \\
\hline
\end{tabular}

ber 1989 so that a variable equal to one on each day of the $\mathbf{4 2}$ day period and zero at other times gave the lowest error sum of squares in a simple linear regression model for admissions using the flu indicator variable alone.

Six indicator variables for the days of the week and one for public holidays were used. Long term linear and quadratic functions of time for the whole seven year period and constant, linear, and quadratic trend terms for six individual years starting 1 April added a further 20 terms. To remove associations due to covariation over periods greater than 20 days, cyclical trends made up of pairs of sine and cosine terms for all integer frequencies over the seven years from two to 127-that is, with wave lengths from 3.5 years down to 20.1 days-were included in the model.

The 126 pairs of cyclical terms, but not the other terms, were eligible for elimination from a multiple linear least squares regression model without autoregressive terms by an automated step down variable selection procedure. The least significant pair was eliminated iteratively unless the step down $F$ test gave a $P$ value $<0.01$.

The cyclical components were determined once only for each diagnostic group, and were not dependent on meteorological or pollution data. There were no missing data associated with modelling calendar terms.

Temperature, humidity, and pollutant were included in the models as untransformed linear terms lagged by one day as suggested by earlier work, ${ }^{81012}$ and six autoregressive terms were included to reduce the effect of correlated errors within weeks.

Single pollutant Poisson models were analysed for each of the eight groupings of emergency admissions. In keeping with other reports a pollutant was said to be significantly associated with admissions if $\mathrm{P}<0.05$, without adjustment for the number of tests, which remained large even though we used a specifc lag.

When there was a significant association in the full model, we were concerned that this might have arisen as an artefact of the complex modelling. We tested for the presence of an association in the same direction in a partial model. Temperature, humidity, and long term trends on the scale of one year were retained in the partial model, but the cyclical components were not, thus testing for the presence of a significant association before allowing for covariation in admissions and pollution over 20 days to one year. For the partial model, the significance test for pollutant was also simplified from a test for a marginal explanatory term in multiple non-linear Poisson regression with overdispersion to a simple test for univariate Pearson correlation of the pollutant with the residuals from a least squares regression of log count.

Further analyses were performed only for the diagnostic grouping, acute myocardial infarction, which had the most consistent associations with pollution. The effect of a warm season, April to September inclusive, and cool season on the relation of admissions to pollution was studied in single and in two pol- 
Table 2 Daily environmental measurements in London, England 1987-94 (selected percentiles)

\begin{tabular}{lcccccc}
\hline & Days & Min & $10 \%$ & Median & $90 \%$ & Max \\
\hline Temperature $\left({ }^{\circ} \mathrm{C}\right.$, midrange) & 2537 & -5 & 9 & 12 & 19 & 29 \\
Relative humidity (\%, average of 0600 & & & & & & \\
$\quad$ and 1500) & 2540 & 40 & 58 & 72 & 86 & 97 \\
$\mathrm{O}_{3}$ (ppb, hourly mean 0900 to 1700) & 2378 & 0 & 3 & 13 & 28 & 94 \\
$\mathrm{NO}_{2}$ (ppb, 24 hourly mean) & 2494 & 8 & 23 & 35 & 53 & 198 \\
$\mathrm{SO}_{2}$ (ppb, 24 hourly mean) & 2316 & 0 & 2 & 6 & 21 & 114 \\
$\mathrm{CO}(\mathrm{ppm}, 24$ hourly mean) & 1931 & 0.2 & 0.6 & 0.9 & 1.8 & 10 \\
Black smoke ( $\mu \mathrm{g} / \mathrm{m}^{3}, 24$ hourly mean) & 2553 & 1 & 7 & 12 & 22 & 62 \\
\hline
\end{tabular}

lutant models. Attributable risk was calculated by the method of Morris et al. ${ }^{13}$

\section{Results}

In London there were 373556 emergency admissions with circulatory diagnoses reported from 1 April 1987 to 31 March 1994 with a daily median of 145 . For the diagnostic subgroups the medians ranged from 10 to 28 a day (table 1). The modelling of long term fluctuations resulted in a variable number of pairs of cyclical terms from two (ICD-9 414) to 83 (other circulatory). These differences were small compared with the residual degrees of freedom, which was usually over 2000 (minimum 1756).
There were fewer data for $\mathrm{CO}$ than for the other pollutants (table 2). Correlations between pollutants (not shown) were all significant at the $P<0.0001$ level, except for the correlation of $\mathrm{O}_{3}$ and $\mathrm{NO}_{2}$ which was not significant. $\mathrm{O}_{3}$ was negatively correlated with the other pollutants, although all other pairwise correlations of pollutants were positive. The largest correlation was between black smoke and $\mathrm{CO}, 0.73$, despite these being measured at different sites.

\section{SINGLE POLLUTANT POISSON MODELS}

Carbon monoxide was significantly associated with combined circulatory diseases, and for the diagnostic subgroups other circulatory and acute myocardial infarction (table 3 ). Sulphur dioxide was significantly related to all circulatory diseases, and to acute myocardial infarction. Nitrogen dioxide was significantly associated with all circulatory diseases, arrhythmia, and acute myocardial infarction. Black smoke was significantly related to all circulatory diseases, angina, and acute myocardial infarction. $\mathrm{O}_{3}$ was negatively associated with hospital admission in all subgroups except for arrhythmia, but not significantly so $(P>0.22)$. All

Table 3 Poisson model results for significance of association of emergency admissions with previous day's air pollutant (\% increase in admissions/unit of pollutant, and relative risk for an increase in concentration from the 10th to 90 th percentile (RR80))

\begin{tabular}{|c|c|c|c|}
\hline & $P$ Value & $\begin{array}{l}\text { Admissions } \\
\% / \text { Unit }\end{array}$ & $\begin{array}{l}\text { Relative risk } \\
(R R 80)(95 \% \text { CI) }\end{array}$ \\
\hline \multicolumn{4}{|c|}{ Acute myocardial infarction ICD-9 410: } \\
\hline $\mathrm{O}_{3}$ & 0.2638 & -0.07 & $0.9825(0.9534$ to 1.0142$)$ \\
\hline $\mathrm{NO}_{2}$ & $0.0024^{\star}$ & 0.09 & $1.0274(1.0084$ to 1.0479$)$ \\
\hline $\mathrm{SO}_{2}$ & $0.0006^{\star}$ & 0.17 & $1.0326(1.0133$ to 1.0511$)$ \\
\hline $\mathrm{CO}^{2}$ & $0.0010^{\star}$ & 2.26 & 1.0275 (1.0096 to 1.0457$)$ \\
\hline Black smoke & $0.0033^{\star}$ & 0.19 & 1.0303 (1.0092 to 1.0528$)$ \\
\hline \multicolumn{4}{|c|}{ Angina pectoris ICD-9 413: } \\
\hline $\mathrm{O}_{3}$ & 0.4887 & -0.06 & $0.9850(0.9469$ to 1.0256$)$ \\
\hline $\mathrm{NO}_{2}$ & 0.0948 & 0.07 & $1.0212(0.9950$ to 1.0457$)$ \\
\hline $\mathrm{SO}_{2}$ & 0.2291 & 0.07 & $1.0133(0.9907$ to 1.0383$)$ \\
\hline $\mathrm{CO}^{\circ}$ & 0.2202 & 1.15 & $1.0140(0.9904$ to 1.0381$)$ \\
\hline Black smoke & $0.0220^{\star}$ & 0.19 & $1.0303(1.0030$ to 1.0593$)$ \\
\hline \multicolumn{4}{|c|}{ Other ischaemic heart disease ICD-9 414: } \\
\hline $\mathrm{O}_{3}$ & 0.2230 & -0.11 & $0.9726(0.9270$ to 1.0214$)$ \\
\hline $\mathrm{NO}_{2}$ & 0.8019 & -0.01 & 0.9970 (0.9667 to 1.0289$)$ \\
\hline $\mathrm{SO}_{2}$ & 0.6495 & -0.03 & $0.9944(0.9651$ to 1.0239$)$ \\
\hline $\mathrm{CO}$ & 0.2676 & -1.07 & $0.9870(0.9588$ to 1.0158$)$ \\
\hline Black smoke & 0.1074 & -0.16 & $0.9752(0.9418$ to 1.0090$)$ \\
\hline \multicolumn{4}{|c|}{ Cardiac arrhythmia ICD-9 427: } \\
\hline $\mathrm{O}_{3}$ & 0.5562 & 0.06 & $1.0153(0.9704$ to 1.0598$)$ \\
\hline $\mathrm{NO}_{2}$ & $0.0382^{\star}$ & 0.09 & $1.0274(1.0006$ to 1.0984$)$ \\
\hline $\mathrm{SO}_{2}$ & 0.2024 & 0.10 & $1.0181(1.0000$ to 1.0448$)$ \\
\hline $\mathrm{CO}$ & 0.0755 & 0.16 & $1.0020(0.9997$ to 1.0043$)$ \\
\hline Black smoke & 0.0755 & 0.16 & $1.0254(0.9958$ to 1.0570$)$ \\
\hline \multicolumn{4}{|c|}{ Heart failure ICD-9 428: } \\
\hline $\mathrm{O}_{3}$ & 0.6708 & -0.02 & $0.9940(0.9604$ to 1.0287$)$ \\
\hline $\mathrm{NO}_{2}$ & 0.8311 & -0.01 & $0.9970(0.9769$ to 1.0194$)$ \\
\hline $\mathrm{SO}_{2}$ & 0.5194 & 0.03 & $1.0057(0.9846$ to 1.0258$)$ \\
\hline $\mathrm{CO}$ & 0.2780 & 0.69 & $1.0084(0.9885$ to 1.0287$)$ \\
\hline Black smoke & 0.4463 & 0.05 & $1.0079(0.9846$ to 1.0309$)$ \\
\hline \multicolumn{4}{|c|}{ Cerebrovascular diseases ICD-9 430-8: } \\
\hline $\mathrm{O}_{3}$ & 0.3055 & -0.06 & $0.9850(0.9560$ to 1.0127$)$ \\
\hline $\mathrm{NO}_{2}$ & 0.1234 & -0.05 & $0.9851(0.9684$ to 1.0045$)$ \\
\hline $\mathrm{SO}_{2}$ & 0.9146 & 0.01 & $1.0019(0.9837$ to 1.0189$)$ \\
\hline $\mathrm{CO}$ & 0.3667 & -0.66 & $0.9920(0.9735$ to 1.0091$)$ \\
\hline Black smoke & 0.7972 & -0.02 & $0.9969(0.9772$ to 1.0176$)$ \\
\hline \multicolumn{4}{|c|}{ Other circulatory diseases: } \\
\hline $\mathrm{O}_{3}$ & 0.4496 & -0.04 & $0.9900(0.9614$ to 1.0220$)$ \\
\hline $\mathrm{NO}_{2}$ & 0.1763 & 0.06 & 1.0182 (1.0000 to 1.0398$)$ \\
\hline $\mathrm{SO}_{2}$ & 0.0621 & 0.10 & $1.0190(0.9994$ to 1.0383$)$ \\
\hline $\mathrm{CO}$ & $0.0040^{\star}$ & 2.56 & $1.0313(1.0126$ to 1.0503$)$ \\
\hline Black smoke & 0.1130 & 0.10 & $1.0158(0.9942$ to 1.0386$)$ \\
\hline \multicolumn{4}{|c|}{ Combined circulatory diseases ICD-9 390-459: } \\
\hline $\mathrm{O}_{3}$ & 0.0686 & -0.11 & $0.9726(0.9436$ to 1.0046$)$ \\
\hline $\mathrm{NO}_{2}$ & $0.0034^{\star}$ & 0.08 & $1.0243(1.0054$ to 1.0448$)$ \\
\hline $\mathrm{SO}_{2}$ & $0.0031^{\star}$ & 0.13 & $1.0248(1.0062$ to 1.0444$)$ \\
\hline $\mathrm{CO}^{2}$ & $0.0012^{\star}$ & 2.31 & $1.0281(1.0100$ to 1.0466$)$ \\
\hline Black smoke & $0.0083^{\star}$ & 0.15 & $1.0238(1.0028$ to 1.0464$)$ \\
\hline
\end{tabular}

$\star P<0.05$. See table 2 for units. 
circulatory diseases approached a negative association with $\mathrm{O}_{3}$ but it was not significant $(\mathrm{P}>0.06)$.

The results were not significant (range of $P$ values from table 3 ) in any of the five single pollutant models for heart failure $(0.27<\mathrm{P}<0.84)$, cerebrovascular disease $(0.12<\mathrm{P}<0.92)$, and other ischaemic heart disease $(0.10<P<0.81)$. Arrhythmias were associated only with $\mathrm{NO}_{2}(\mathrm{P}=0.04)$, angina was associated only with black smoke $(\mathrm{P}=0.02)$, and other circulatory disease was associated only with $\mathrm{CO}(\mathrm{P}=0.004)$.

Acute myocardial infarction alone among the diagnostic subgroups was associated with more than one pollutant.

Table 4 Acute myocardial infarction: one and two pollutant models with cool and warm season (diagonal elements (bold) are single pollutant models, off diagonal elements are test pollutant modelled with a second pollutant)

\begin{tabular}{|c|c|c|c|c|c|}
\hline \multirow[b]{2}{*}{ Test pollutant } & \multicolumn{5}{|c|}{ Second pollutant } \\
\hline & $\mathrm{O}_{3}$ & $\mathrm{NO}_{2}$ & $\mathrm{SO}_{2}$ & $C O$ & Black smoke \\
\hline \multicolumn{6}{|l|}{$\mathrm{O}_{3}(\mathrm{ppb}):$} \\
\hline \multicolumn{6}{|l|}{ Cool season: } \\
\hline$P$ value & 0.22 & 0.72 & 0.91 & 0.93 & 0.95 \\
\hline Coefficient & -0.0013 & 0.0004 & 0.0001 & -0.0001 & 0.0001 \\
\hline Lower 95\% & -0.0033 & -0.0019 & -0.0021 & -0.0027 & -0.0021 \\
\hline Upper $95 \%$ & 0.0008 & 0.0027 & 0.0024 & 0.0024 & 0.0023 \\
\hline \multicolumn{6}{|l|}{ Warm season: } \\
\hline$P$ value & 0.48 & 0.39 & 0.26 & 0.34 & 0.34 \\
\hline Coefficient & -0.0005 & -0.0006 & -0.0009 & -0.0009 & -0.0007 \\
\hline Lower 95\% & -0.0018 & -0.0020 & -0.0024 & -0.0025 & -0.0020 \\
\hline Upper $95 \%$ & 0.0009 & 0.0008 & 0.0006 & 0.0009 & 0.0007 \\
\hline \multicolumn{6}{|l|}{$\mathrm{NO}_{2}(\mathrm{ppb}):$} \\
\hline \multicolumn{6}{|l|}{ Cool season: } \\
\hline$P$ value & $0.0004^{\star}$ & $0.0020^{\star}$ & 0.15 & 0.84 & 0.23 \\
\hline Coefficient & 0.0022 & 0.0013 & 0.0008 & 0.0002 & 0.0008 \\
\hline Lower $95 \%$ & 0.0010 & 0.0005 & -0.0003 & -0.0015 & -0.0005 \\
\hline Upper 95\% & 0.0034 & 0.0022 & 0.0018 & 0.0019 & 0.0021 \\
\hline \multicolumn{6}{|l|}{ Warm season: } \\
\hline$P$ value & 0.49 & 0.53 & 0.65 & 0.90 & 0.63 \\
\hline Coefficient & 0.0004 & 0.0003 & -0.0003 & 0.0001 & 0.0003 \\
\hline Lower $95 \%$ & -0.0007 & -0.0007 & -0.0018 & -0.0016 & -0.0009 \\
\hline Upper $95 \%$ & 0.0014 & 0.0014 & 0.0011 & 0.0018 & 0.0016 \\
\hline \multicolumn{6}{|l|}{$\mathrm{SO}_{2}(\mathrm{ppb}):$} \\
\hline \multicolumn{6}{|l|}{ Cool season: } \\
\hline$P$ value & $0.0005^{\star}$ & $0.03^{\star}$ & $0.0004^{\star}$ & $0.02^{\star}$ & $0.03^{\star}$ \\
\hline Coefficient & 0.0025 & 0.0015 & 0.0021 & 0.0020 & 0.0015 \\
\hline Lower $95 \%$ & 0.0011 & 0.0001 & 0.0009 & 0.0003 & 0.0001 \\
\hline Upper 95\% & 0.0039 & 0.0030 & 0.0033 & 0.0037 & 0.0029 \\
\hline \multicolumn{6}{|l|}{ Warm season: } \\
\hline$P$ value & 0.70 & 0.49 & 0.53 & 0.32 & 0.58 \\
\hline Coefficient & 0.0004 & 0.0009 & 0.0006 & 0.0013 & 0.0006 \\
\hline Lower $95 \%$ & -0.0016 & -0.0016 & -0.0013 & -0.0013 & -0.0014 \\
\hline Upper $95 \%$ & 0.0024 & 0.0034 & 0.0025 & 0.0039 & 0.0026 \\
\hline \multicolumn{6}{|l|}{ CO (ppb): } \\
\hline \multicolumn{6}{|l|}{ Cool season: } \\
\hline$P$ value & $0.001^{\star}$ & 0.15 & 0.39 & $0.02^{\star}$ & 0.38 \\
\hline Coefficient & 0.0324 & 0.0205 & 0.0083 & 0.0227 & 0.0100 \\
\hline Lower $95 \%$ & 0.0127 & -0.0074 & -0.0107 & 0.0074 & -0.0121 \\
\hline Upper $95 \%$ & 0.0520 & 0.0483 & 0.0273 & 0.0380 & 0.0321 \\
\hline \multicolumn{6}{|l|}{ Warm season: } \\
\hline$P$ value & 0.63 & 0.63 & 0.55 & 0.40 & 0.39 \\
\hline Coefficient & 0.0112 & 0.0154 & -0.0160 & 0.0187 & 0.0243 \\
\hline Lower $95 \%$ & -0.0348 & -0.0477 & -0.0683 & -0.0250 & -0.0308 \\
\hline Upper $95 \%$ & 0.0572 & 0.0786 & 0.0363 & 0.0625 & 0.0794 \\
\hline \multirow{2}{*}{\multicolumn{6}{|c|}{$\begin{array}{l}\text { Black smoke }\left(\mu \mathrm{g} / \mathrm{m}^{3}\right): \\
\text { Cool season: }\end{array}$}} \\
\hline & & & & & \\
\hline$P$ value & $0.0006^{\star}$ & 0.23 & 0.10 & 0.13 & $0.002^{\star}$ \\
\hline Coefficient & 0.0033 & 0.0014 & 0.0015 & 0.0019 & 0.0024 \\
\hline Lower 95\% & 0.0014 & -0.0009 & -0.0003 & -0.0006 & 0.0009 \\
\hline Upper $95 \%$ & 0.0051 & 0.0037 & 0.0033 & 0.0043 & 0.0039 \\
\hline \multicolumn{6}{|l|}{ Warm season: } \\
\hline$P$ value & 0.84 & 0.96 & 0.86 & 0.79 & 0.82 \\
\hline Coefficient & -0.0003 & 0.0001 & 0.0003 & -0.0006 & 0.0003 \\
\hline Lower $95 \%$ & -0.0033 & -0.0036 & -0.0031 & -0.0050 & -0.0026 \\
\hline Upper $95 \%$ & 0.0027 & 0.0037 & 0.0037 & 0.0038 & 0.0033 \\
\hline
\end{tabular}

$\star \mathrm{P}<0.05$.

Cool season is October to March, warm season is April to September. Coefficient $=$ Poisson regression coefficient-for example, $\%$ admissions per unit of pollutant $=(\exp (\operatorname{coeff})-1) \times 100$.
SINGLE POLLUTANT PARTIAL MODELS

Significant associations found with a Poisson model were tested also in the partial modelthat is, without sine and cosine terms and without the Poisson assumption. Only the associations with acute myocardial infarction were significant in both models. For $\mathrm{CO}$ the associations became undetectable with all circulatory diseases, $\mathrm{P}=0.61$, and with other circulatory disease, $\mathrm{P}=0.77$ (the direction of this association was reversed) whereas the association with acute myocardial infarction was consistent $(\mathrm{P}=0.0005)$. For $\mathrm{SO}_{2}$ the association with all circulatory diseases was reversed $(\mathrm{P}=0.54)$, whereas an association with acute myocardial infarction in the same direction was detected $(\mathrm{P}=0.01)$. For $\mathrm{NO}_{2}$ the associations with all circulatory diseases $(P=0.22)$ and arrhythmia $(P=0.12)$ were not detectable, but the association with acute myocardial infarction was evident $(\mathrm{P}=0.002)$. For black smoke the associations with all circulatory diseases $(P=0.23)$ and angina $(P=0.37)$ were not detectable, but for acute myocardial infarction the association was again evident $(\mathrm{P}=0.002)$.

The attributable numbers of cases of acute myocardial infarction were calculated for each day from the full Poisson model's fitted number of admissions under all the observed conditions including the level of pollutant for that day, and then changing pollutant to the minimum concentration (table 2)..$^{13}$ The sum of the differences converted to a percentage of admissions ( $95 \%$ confidence limits ( $95 \%$ CIs)) were: $\mathrm{O}_{3}-1.0 \%(-2.8 \%$ to $0.8 \%), \mathrm{SO}_{2} 1.7 \%$ (0.6 to 2.6 ), CO $2.1 \%$ (0.7 to 3.5 ), black smoke $2.5 \%$ (0.8 to 4.3 ), $\mathrm{NO}_{2} 2.7 \%$ (0.8 to 4.6).

ACUTE MYOCARDIAL INFARCTION, SEASON, AND TWO POLLUTANT MODELS

As acute myocardial infarction was the only diagnosis for which the results were consistent between full and partial models, we examined for acute myocardial infarction only the influence of a cool (October to November) and warm season (April to September). Single pollutant and then two pollutant Poisson models were used. In the single pollutant models, as before, all four pollutants other than $\mathrm{O}_{3}$ were significant; however, they were only significant in the cool season and not in the warm season (table 4). In two pollutant models, again $\mathrm{O}_{3}$ was not significant. All the other pollutants were significant in combination with $\mathrm{O}_{3}$, but in the cool season only. Only $\mathrm{SO}_{2}$ was significant with a pollutant other than $\mathrm{O}_{3} . \mathrm{SO}_{2}$ was significant with all the other pollutants $\left(\mathrm{NO}_{2} \mathrm{P}=0.033\right.$, CO $\mathrm{P}=0.021$, black smoke $\mathrm{P}=0.031$ ), but again only in the cool season.

\section{Discussion}

The evidence from previous studies for a consistent association between $\mathrm{O}_{3}$ and circulatory disease is weak, and for a positive association it is weaker still. In the present data, there is a complete absence of an association with $\mathrm{O}_{3}$ compatible with cardiovascular toxicity, and there is even a suggestion of a negative associ- 
ation. These findings are in agreement with those of Schwartz and Morris ${ }^{14}$ who did not find an association with hospital admissions for people over 64 years old for ischaemic heart disease, heart failure, or arrhythmia, despite looking for an association with concentrations of $\mathrm{O}_{3}$ on the same day and up to two days before, adjusting for a warm season, and extensive modelling of temperature and humidity. No association of $\mathrm{O}_{3}$ on the same day and lagged by one and two days with all year circulatory deaths in London was found for 1987-92: for the warm season alone there was a significant positive association at lag 0 , whereas the results for the few observations in the cool season were consistent with an effect of equal magnitude but in the opposite direction. ${ }^{8}$ Cardiovascular deaths in Lyon, France, were also not associated with $\mathrm{O}_{3}$ (estimated relative risk of 1 ) ${ }^{15}$ Admissions for heart failure under Medicare and $\mathrm{O}_{3}$ have been analysed from seven cities in the United States: two cities had positive associations, four had negative, and one had neutral; only the associations for New York and Los Angeles were significant $(P<0.05)$, and these two results were in opposite directions. ${ }^{13}$

The balance of evidence for an association of black smoke with circulatory deaths is not strong, particularly in London, and this weakens the case for an association with acute myocardial infarction, which has a high immediate mortality. Black smoke and circulatory deaths were not associated in London for all year, cool season, or warm season. ${ }^{8}$ In Lyon there was also no significant association with particulate mater with an aerodiameter of $<13 \mu \mathrm{m}$ (PM13), ${ }^{15}$ and in Athens none for black smoke. ${ }^{16}$ On the other hand there were significant positive associations of deaths in Philadelphia and Cincinnati with total suspended particles ${ }^{17} 18$ and in Birmingham, United Kingdom with PM10. ${ }^{19}$ Cardiovascular morbidity, rather than mortality, has perhaps more consistent associations with particles. In Detroit, PM10 was associated with ischaemic heart disease in the $>64$ year age group, and in our London data with acute myocardial infarc-

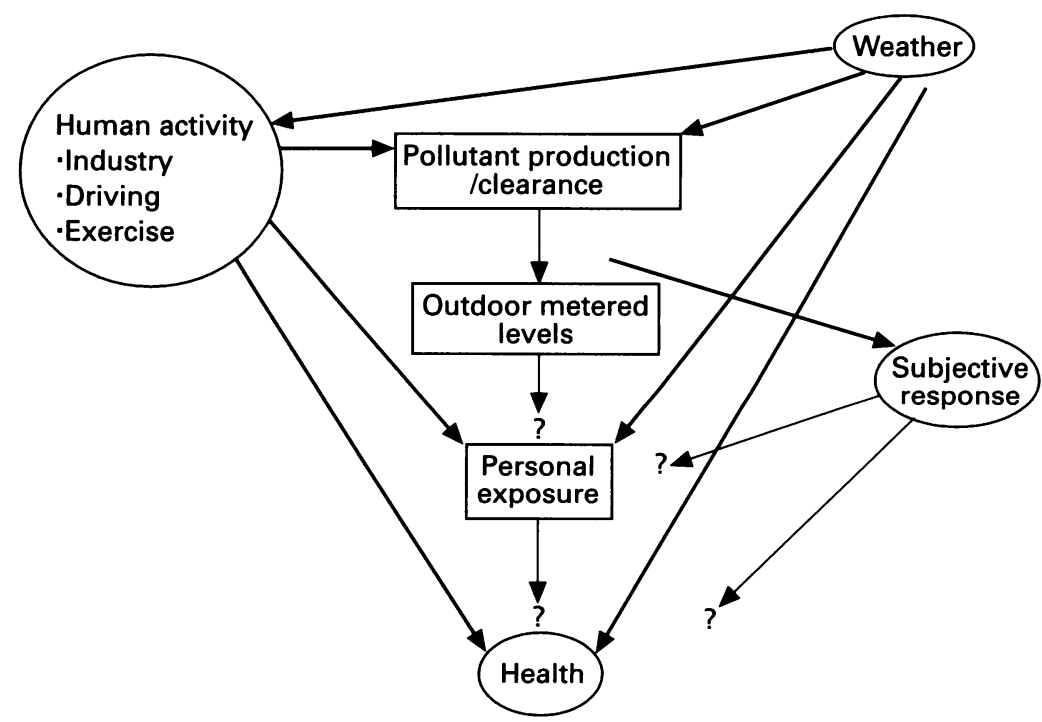

Short term relation between outdoor metered air pollution and health. tion, angina, and all circulatory diseases, but in Birmingham there was no association with admissions for ischaemic heart disease. ${ }^{19}$ An association with heart failure has been reported for elderly people,${ }^{14}$ but there was none in our data for all ages combined. In Beijing there was no association between mortality from pulmonary heart disease and total suspended particles. ${ }^{20}$

We found an association between $\mathrm{SO}_{2}$ and acute myocardial infarction and all circulatory diseases. The partial model association with all circulatory diseases was, however, not significant and in the opposite direction, whereas it was significant and in the same direction for acute myocardial infarction. Again mortality from circulatory disease in London did not reflect this association either for all year, or cool, or warm seasons. ${ }^{8}$ In Lyon ${ }^{15}$ and Beijing, ${ }^{20}$ however, associations have been found; but not in Athens, ${ }^{16}$, or two other French cities despite examining at least 10 different lags. ${ }^{21}$

Associations of $\mathrm{CO}$ with heart failure in elderly people were found in several cities in the United States, ${ }^{13}$ and with ischaemic heart disease in Detroit, ${ }^{14}$ but were not apparent in our data. There is one previous report of associated mortality, which is based on one year's data in elderly people of Sao Paolo. ${ }^{22}$

In the present data, only associations with acute myocardial infarction were supported by significant associations in the partial model: black smoke $\mathrm{P}=0.002, \mathrm{NO}_{2} \mathrm{P}=0.002, \mathrm{SO}_{2}$ $\mathrm{P}=0.01$, CO $\mathrm{P}=0.0005$. There are published accounts from many cities of a lack of association of air pollution with cardiovascular deaths. Our data on all circulatory diseases and diagnostic subgroups, other than acute myocardial infarction, are consistent with those conclusions. For acute myocardial infarction, however, our positive associations for black smoke, $\mathrm{NO}_{2}$, and $\mathrm{SO}_{2}$ with emergency admissions are hard to reconcile with a lack of association with circulatory deaths ${ }^{8}$ although for acute myocardial infarction the time to emergency hospital admission compared with the time to death is likely to be less variable in relation to a provocation-such as air pollution-and is probably therefore a more sensitive outcome.

Significant associations might, however, arise solely because factors that affect the clearance and creation of air pollution-such as the weather and driving motor vehiclesalso have a direct effect on human behaviour and on acute health outcomes (figure). Although we have modelled temperature and humidity, there are other factors-for example, wind and rain-which affect air pollution and also affect the amount of physical exercise taken and the duration of time spent outdoors, where levels of air pollution are generally different from indoors. With so much potential for confounding, and with a good many conflicting results to be found in the scientific literature, we chose to place the statistical emphasis on the direction and consistency of the relations ( $P$ values) rather than on estimat- 
ing the size of effects from the models which produce the largest effects, as has usually been done.

The present results for $\mathrm{CO}$ taken with the dearth of published studies relating it to cardiovascular disease in general and acute myocardial infarction in particular make a case for further study of $\mathrm{CO}$. Average concentrations over one hour at a kerbside monitor can reach 25 ppm. ${ }^{23}$ Breathing CO at $50 \mathrm{ppm}$ for one hour increased carboxyhaemoglobin by a factor of two, and reduced symptom limited exercise capacity in patients with stable angina pectoris as reviewed by Strom et al. ${ }^{24}$ Thus the risk of myocardial ischaemia when pushing a lawn mower or shovelling snow ${ }^{25}$ is increased by the proximity of an internal combustion engine. We have shown that fluctuations in background concentrations of $\mathrm{CO}$ are an additional risk factor for myocardial infarction in the population, and this effect could be due to an increased risk of infarction during exercise when environmental concentrations of $\mathrm{CO}$ have risen within the preceding 24 hours.

All the results for $\mathrm{O}_{3}$ were not significant. For the other pollutants the only consistent associations were with acute myocardial infarction. Biologically plausible mechanisms have been advanced by which emissions, mainly from motor vehicles, might trigger circulatory disorders. Our results strengthen the case for the existence of a causal link with myocardial infarction.

1 Seaton A, MacNee W, Donaldson K, Godden D. Particulate air pollution and acute health effects. Lancet 1995;345:1768.

2 Lipfert FW, Wyzga RE. Air pollution and mortality: issues and uncertainties. Fournal of the Air and Waste Managemen Association 1995;45:949-66.

3 Schwartz J. Air pollution and daily mortality: a review and meta analysis. Environ Res 1994;64:36-52.

4 Ostro $B$. The association of air pollution and mortality: examining the case for inference. Arch Environ Health 1993;48:336-42.

5 Lipfert FW. A critical review of the association between demands for hospital services and air pollution. Environ Health Perspect 1993;101(suppl 2):229-68.

6 Buck SF. A method of estimation of missing values in multivariate data suitable for use with an electronic computer. fournal of the Royal Statistical Society (B) 1960;22:302-6. 7 Quality of Urban Air Review Group. Urban air quality in the United Kingdom

8 Anderson HR, Ponce de Leon A, Bland MJ, Bower JS, Strachan DP. Air pollution and daily mortality in London: 1987-92. BMF 1996;312:665-9.

9 Government Statistical Service. Hospital episode statistics, vol 1 , finished consultant episodes by diagnosis, operation, and speciality: England financial year 1993-94. Crown Copyright. London: The Government Statistical Service, right. London: The Govern

10 de Leon A, Anderson HR, Bland MJ, Strachan DP. Effects of air pollution on daily hospital admissions for respiratory disease in London, between $1987-8$ and 1991-2. 7 Epidemiol Community Health 1996;33(suppl 1):S63-70.

11 Katsouyanni K, Zmirou D, Spix C, Sunjer J, Schouten JP, Ponka A, et al. Short-term effects of air pollution on health: a European approach using epidemiologic time series data. a European approach using epidemiologic time series data. The APHEA project: design, objectives, background

12 Verhoeff AP, Hoek G, Schwartz J, van Wijnen JH. Air pollution and daily mortality in Amsterdam. Epidemiology 1996; 7225-30.

13 Morris RD, Naumova EN, Munasinghe RL. Ambient air pollution and hospitalization for congestive heart failure among the elderly in seven large American cities. Am f among the elderly in seven large
Public Health 1995;85:1361-5.

14 Schwartz J, Morris R. Air pollution and hospital admissions for cardiovascular disease in Detroit, Michigan. Am $\mathcal{F}$ Epidemiol 1995;142:23-35.

15 Zmirou D, Barumandzadeh T, Balducci F, Ritter P, Laham G, Ghilardi J-P. Short term effects of air pollution on mortality in the city of Lyon, France 1985-90. $₹$ Epidemiol Community Health 1996;50(suppl 1):S30-5.

16 Katsouyanni K, Karakatsani A, Messari I, Touloumi G Hatzakis A, Kalandidi A, Trichoploulos D. Air pollution and cause specific mortality in Athens. F Epidemiol Community Health 1990;44:321-4.

17 Schwartz J, Dockery DW. Increased mortality in Philadelphia associated with daily air pollution concentrations. $\mathrm{Am}$ Rev Respir Dis 1992;145:600-4.

18 Schwartz J. Total suspended particulate matter and daily mortality in Cincinnati, Ohio. Environ Health Perspect mortality in Cincin

19 Wordley J, Walters S, Ayres JG. Short term variations in hospital admissions and mortality and particulate air pollution. Occup Environ Med 1997;54:108-16.

$20 \mathrm{Xu} \mathrm{X}$, Gao J, Dockery DW, Chen Y. Air pollution and daily mortality in residential areas of Beijing, China. Arch Environ Health 1994;49:216-22.

21 Derriennic F, Richardson S, Mollie A, Lellouch J. Short-term effects of sulphur dioxide pollution on mortality in two French cities. Int $₹$ Epidemiol 1989;18:18697.

22 Saldiva PH, Pope CA 3rd, Schwartz J, Dockery DW, Lichtenfels AJ, Salge JM, et al. Air pollution and mortality in elderly people: a time-series study in Sao Paulo, Brazil. Arch Environ Health 1995;50:159-63.

23 Bertorelli V, Derwent R. Air quality $A$ to $Z$ : a directory of air quality data for the United Kingdom in the 1990s. London: The Meteorological Office, 1995.

24 Strom J, Alfredson L, Malmfors T. Carbon monoxide: causation and aggravation of cardiovascular diseases-a review of the epidemiologic and toxicologic literature. Indoor Environment 1995;4:322-33.

25 Petch M. Triggering a heart attack. BMF 1996;312:459. 